\title{
A PCR-based Assay for Reporter Gene Expression
}

\author{
Peter Sperisen, San Ming Wang, Patrick Reichenbach, \\ and Markus Nabholz
}

ISREC, CH 1066 Epalinges, Switzerland

Transient transfection is a widely used tool for the identification of cis-acting regulatory elements. These elements are detected by their effect on the expression of a reporter gene, which is quantified by measuring the reporter gene product in the form of $m R N A$, protein (hGH), or enzymes (CAT, luciferase). Measurements of mRNA levels have several advantages over enzyme or protein assays. However, mRNA quantification by RNase protection or 51 mapping has considerably lower signal-to-background ratio than protein assays and is therefore less sensitive. In this paper we report the development of a system that takes advantage of the polymerase chain reaction (PCR) to quantify rabbit $\beta$-globin reporter gene expression. Cells are co-transfected with constructs whose activity is to be tested and a reference plasmid with a small deletion in the second exon of the $\beta$ globin gene. We show that the ratio of the two amplified CDNA signals is a highly reliable measure of test gene expression. The sensitivity of this assay is at least $\mathbf{1 0 0 0}$. fold higher than RNase protection.
$\mathbf{T}$ he usefulness of transient transfection depends largely on the reliability of the reporter gene detec- tion method. One of the most widely used reporter genes for comparison of promoter activity in mammalian cells

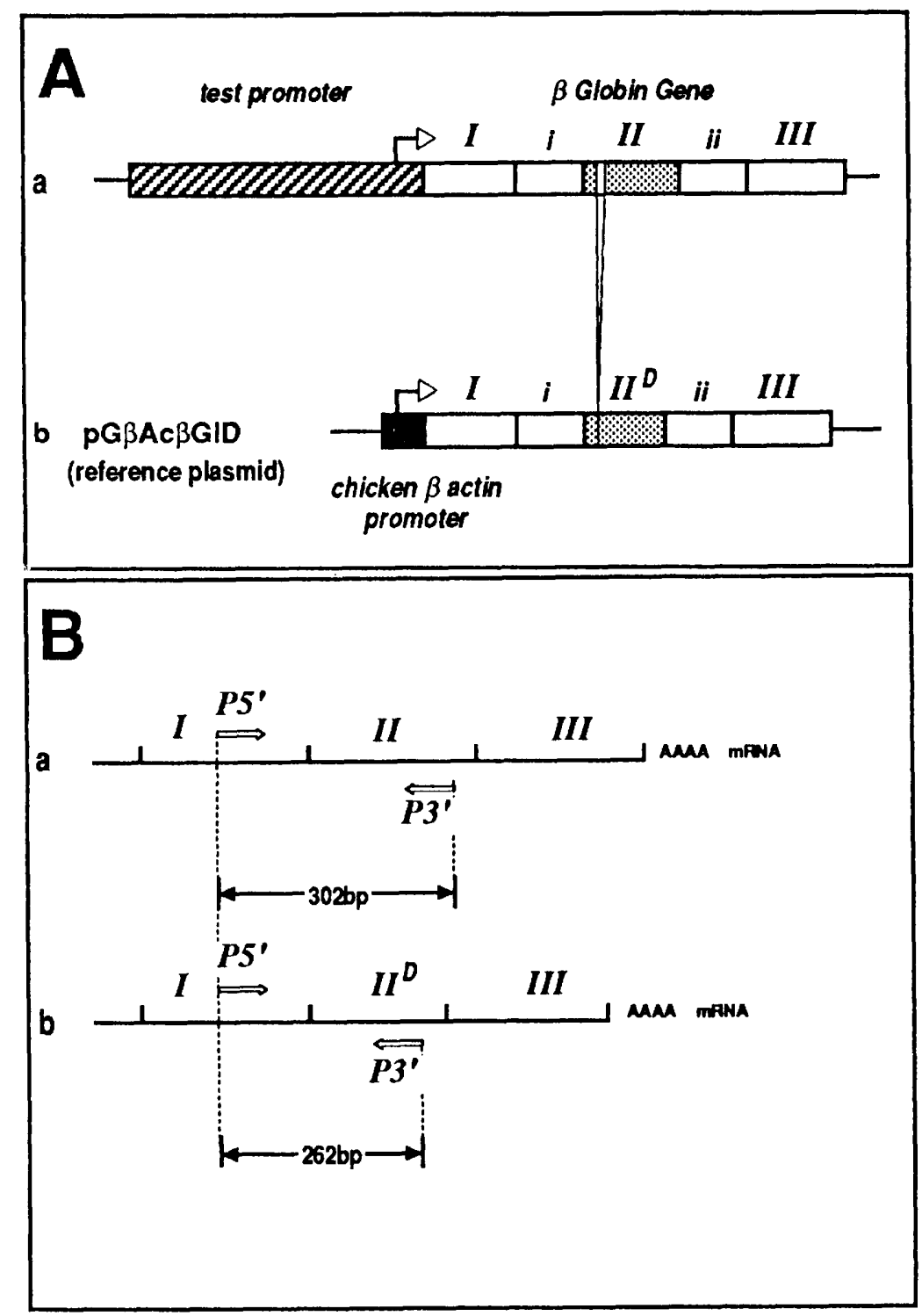

FIGURE 1 The assay. (A) Cells are co-transfected with a defined ratio of the promoter construct to be tested $(a)$ and the reference plasmid $(b)$. (B) R.NA is extracted from the trans. fectants by a standard method and treated with DNase I to remove remaining plasmid DNA. An aliquot of the RNA from $10^{5}$ cells is reverse-transcribed from a poly(dT) primer with AMV reverse transcriptase. The cDNA is amplified with $T u q$ polymerase using primers that span an intron and the deletion in the control plasmid (P5', P3'). 
is that encoding for the bacterial enzyme chloramphenicol acetyltransferase (CAl). Although methods for quantifying $\mathrm{mRNA}$ levels are less sensitive than CAT-enzyme assays, they have three major advantages: (1) they allow the introduction of adequate controls to normalize for variations in transfection efficiency and sample processing; (2) the effect of protein translation inhibitors on reporter gene expression inducible by extracellular stimuli can be tested; and (3) meaningful interpretation of the response kinetics of inducible expression is possible.
To combine the levels of sensitivity obtained with enzyme assays with advantages of measuring mRNA levels, we have developed an assay based on PCR amplification of reporter gene transcripts. As previously shown,,$^{(1-3)}$ very small amounts of specific mRNA can be amplified by PCR. Because the efficiency of amplification can vary substantially among identical samples, it has been difficult to quantify mRNA levels by PCR. For mRNAs transcribed from resident genes, this problem can be solved by co-amplification of the cDNA with a reference DNA template that serves as an amplification stan- dard. The two DNAs are identical except for the presence of a mutated restriction site or a small insertion in the reference DNA. ${ }^{(4)}$ If the difference between cDNA and reference DNA does not affect amplification, the ratio of the two PCR products should remain constant throughout the amplification process irrespective of cycle number, changes in primer and dNTP consumption, production of inhibitory pyrophosphates, or other factors. Applying this idea to the quantification of reporter gene activity in transient transfection assays, we co-transfected cells with a reference plasmid in which
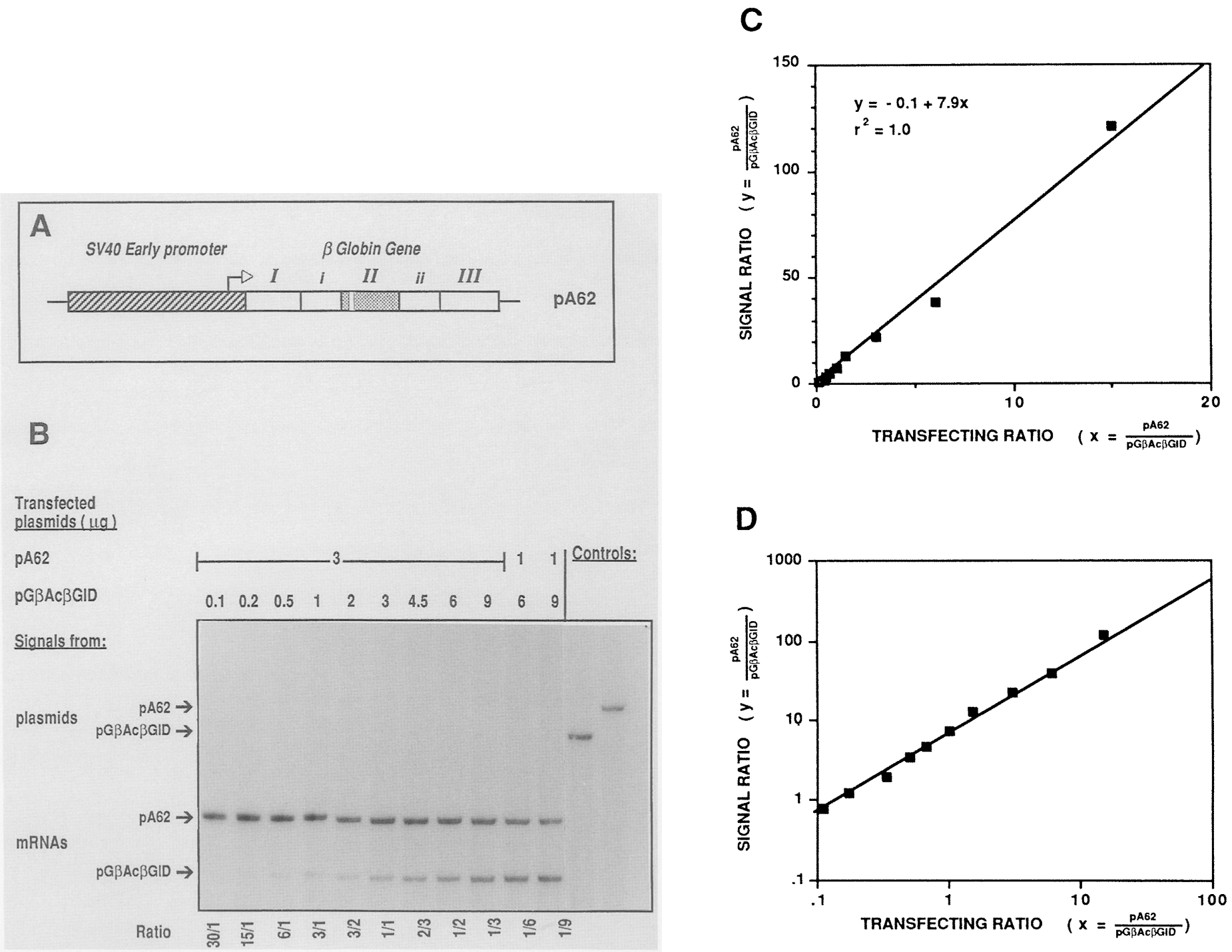

FIGURE 2 Linearity between signal ratio and the ratio of transfecting plasmids. (A) Schematic representation of the plasmid pA62 which was co-transfected with the reference plasmid pGBAcBGID at different ratios into PC60 cells. $(B)$ The amounts transfected are indicated on top of each lane and the resulting ratios below. Total cytoplasmic R. $\mathrm{A}$ was extracted and assayed as described in Fig. 1 (see also Methods). As controls, we used RNA from mock-transfected PC60 cells to which 10 pg of pA62 or pGBAc $\beta G I D$ was added after reverse transcription. ( $C$ and $D$ )

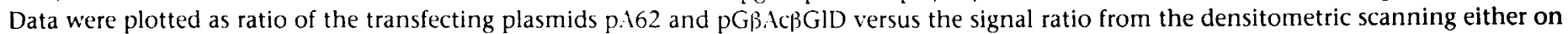
a normal $(C)$ or on a $\log (D)$ scale. 
the strong constitutive chicken $\beta$-actin promoter controls transcription of the rabbit $\beta$-globin gene and promoter constructs whose activity we wish to test (Fig. 1A). The mRNAs derived from these two plasmids differ by a 40-bp deletion in the second $\beta$-globin exon of the reference plasmid. RNA is extracted from the transfected cells, reverse-transcribed, and amplified in a PCR reaction using a 5 'oligonucleotide that hybridizes with the first exon (P5') and a 3'oligonucleotide that hybridizes with the second exon downstream of the 40-bp deletion (P3') (Fig. 1B). Amplified cDNAs can be distinguished from each other because of the deletion in the reference plasmid. cDNA signals can also be separated from amplified plasmid (that has escaped DNase I treatment of the RNA samples), because of the presence of the first intron in the latter (see, e.g., Fig. 3A).

\section{METHODS}

\section{Plasmids}

Plasmids were prepared as described. (5) pA62 has been described previously. ${ }^{(6)}$ Plasmid pG $\beta A c \beta G l$ was constructed in two steps. First, the 283-bp XholBamHI fragment of pWE-TAC, (7) containing the chicken $\beta$-actin promoter from position -277 to +6 , $^{(8)}$ was inserted into pGEM3Zf(+) (Promega) digested with BamHI and Sall. Second, the resulting plasmid was digested with BamHI, blunt-ended with Klenow, and ligated with the 1664-bp Pvull fragment from Z-pCRI/pRChr $\beta G-1,{ }^{(9)}$ containing the genomic rabbit $\beta$ globin gene.

In the plasmid $p G \beta A c \beta G I D$, the Accl-Hindll fragment of the second exon was replaced by a 40-bp shorter fragment. This fragment was made by PCR amplification of pG $\beta A c \beta G l$ using a $5^{\prime}$ oligonucleotide $\left(5^{\prime}\right.$-ggggtctacCCTCTGCACATGCTGT $-3^{\prime}$ ) in which an Accl site (underlined) was linked to the sequence $40 \mathrm{bp}$ downstream of the original ACCI (position +283) site of the rabbit $\beta$-globin gene (uppercase) together with a $3^{\prime}$ oligonucleotide that included the HindIII site, at position +657 of the $\beta$-globin gene, in its $5^{\prime}$ end (5'-GAGACAACTGTTGGTAACAGAGGAG-3').

\section{Cell cultures and transfections}

The PC60.21.14.4 cells have been described in previous publications. ${ }^{(10,11)}$ They were transfected according to Queen and Baltimore ${ }^{(12)}$ with the indicated amounts of plasmid DNA without carrier DNA in $200 \mathrm{mg} / \mathrm{ml}$ DEAEdextrane (Pharmacia). Actinomycin D (Boehringer Mannheim, FRG) was used at a concentration of 5 u.M.

Total cytoplasmic RNA was isolated as described ${ }^{(13)}$ and dissolved in $\mathrm{H}_{2} \mathrm{O}$.

\section{CDNA Synthesis and PCR}

One microgram of DNase I-treated total cytoplasmic RNA was incubated for $2 \mathrm{~min}$ at $90^{\circ} \mathrm{C}$ together with $0.25 \mu \mathrm{g}$ of poly-d $(\mathrm{T})_{20}$ (dissolved in $\mathrm{H}_{2} \mathrm{O}$ at a concentration of $0.25 \mu \mathrm{g} / \mu \mathrm{l}$, Pharmacia) and put on ice. The incubation mixture was adjusted to $20 \mu \mathrm{l}$ containing 2 $\mathrm{ul}$ of $10 \mathrm{x}$ PCR buffer $(500 \mathrm{mM} \mathrm{KCl}, 100$ $\mathrm{mM}$ Tris- $\mathrm{HCl}, \mathrm{pH} 8.3,150 \mathrm{mM} \mathrm{MgCl}_{2}$ ), dNTPs (500 $\mu \mathrm{M}$ final concentration of each nucleotide, Pharmacia), DTT (1 $\mathrm{mm}$ final concentration), 15 units of

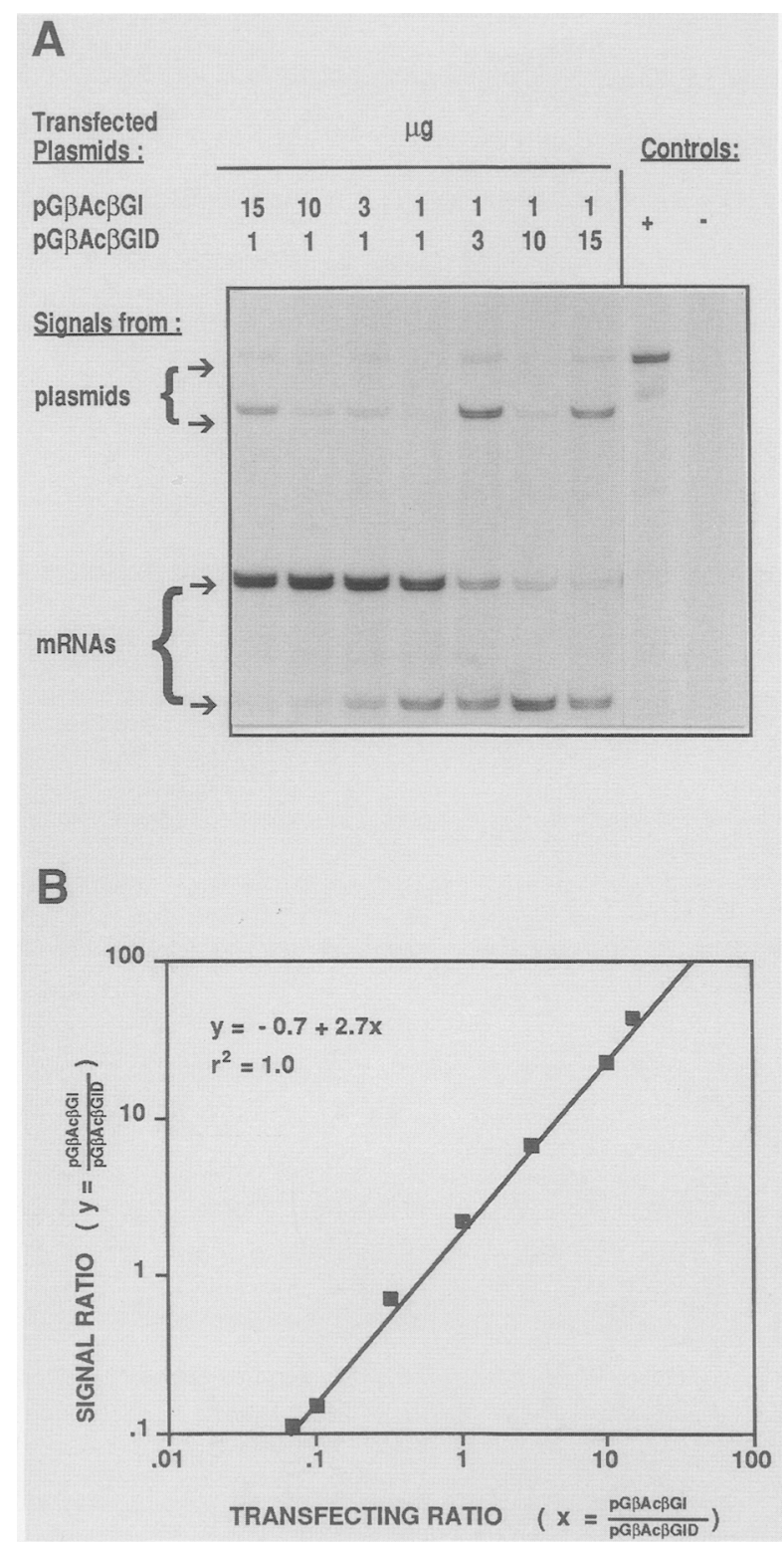

FIGURE 3 C is unequal to 1. (A) PC60 cells were co-transfected with the indicated amounts of the plasmids $p G \beta A c \beta G I$ and $p G \beta A c \beta G I D$. As a positive control, we used $10 \mathrm{pg}$ of the plasmid pGPACBGI. (B) Data were plotted as ratio of the transfected plasmids versus the measured signal ratio on a log-scale. 


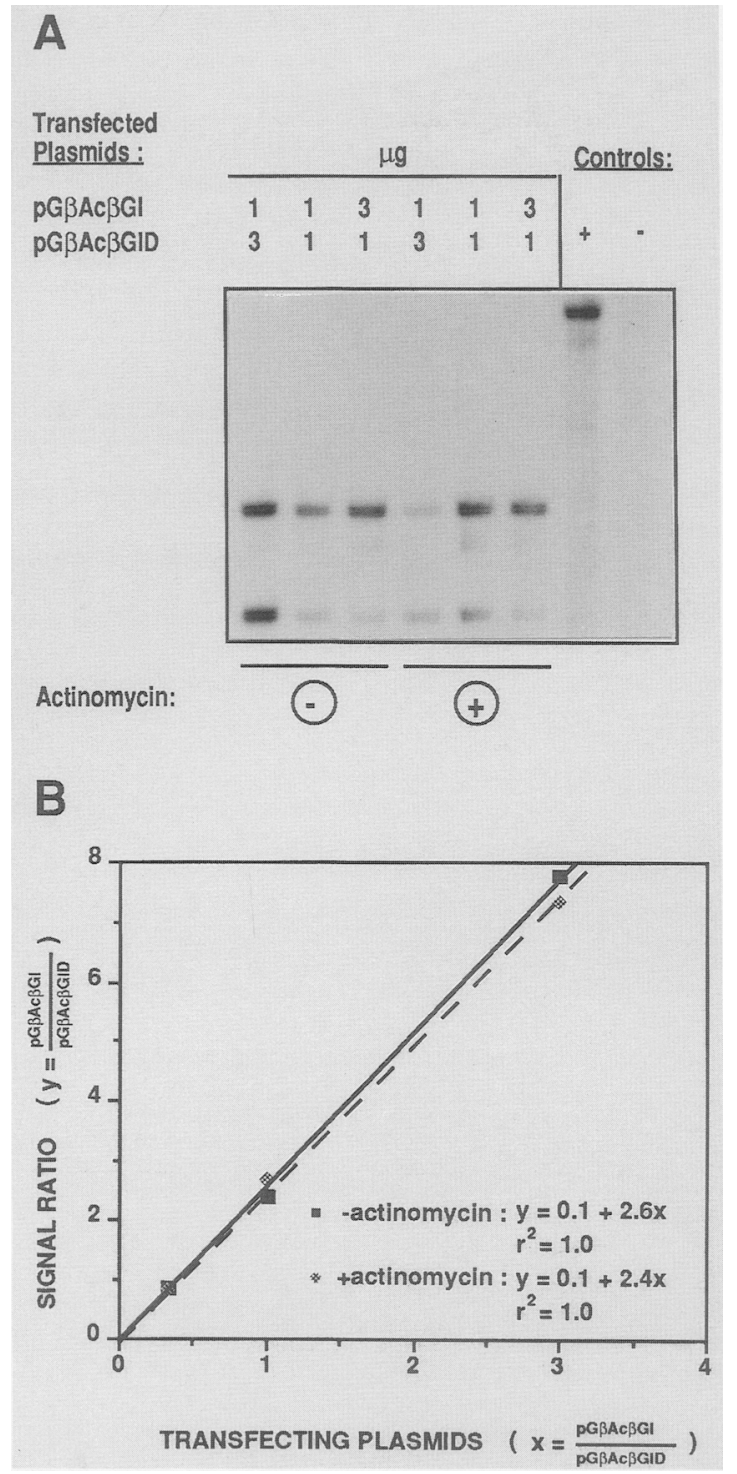

FIGURE 4 No difference in the half-life of the two mRNAs. (A) pG $\beta A c \beta G$ and $p G \beta A c \beta G I D$ were transfected into PC60 cells using different ratios. After the transfection, cells were split and $42 \mathrm{hr}$ later actinomycin was added for another $6 \mathrm{hr}$ to one part of the transfection. Controls are the same as described in Fig. 3B. (B) Plot of the resulting signal ratios versus the input plasmid ratios.

AMV reverse transcriptase (Pharmacia), and 10 units of RNasin (Promega). After cDNA synthesis ( $1 \mathrm{hr}$ at $\left.42^{\circ} \mathrm{C}\right), 30$ $\mu l$ of $1 \times$ PCR buffer containing dNTP (166 $\mu \mathrm{M}$ final concentration of each nucleotide, including $3 \mu \mathrm{Ci}$ of $[\alpha-$ ${ }^{32}$ P]dATP, Amersham), 100 pmoles of each primer $\left(\mathrm{P5}^{\prime}, 5^{\prime}\right.$-TCCCCCAAAACAGACAGAATGG-3' ; P3 ', 5' -TCACAGTGCCAGTTCACTCAGC-3' , prepared on an Applied Biosystems 380B automated synthesizer), 1 unit of Taq polymerase (Cetus), and $10 \mu \mathrm{g}$ RNase $A$, were added. After $3 \mathrm{~min}$ of denaturation at $94^{\circ} \mathrm{C}$, samples were amplified by 40 cycles of $94^{\circ} \mathrm{C}$ for 70 sec, $58^{\circ} \mathrm{C}$ for $90 \mathrm{sec}$, and $72^{\circ} \mathrm{C}$ for 90 sec. An aliquot of each reaction mixture was denatured in $5 \mu \mathrm{l}$ of loading buffer $(80 \%$ formamide, $5 \mathrm{~mm}$ EDTA, $\mathrm{pH} \quad 7.0, \quad 0.03 \%$ bromphenol blue, $0.03 \%$ xylene cyanole FF) at $95^{\circ} \mathrm{C}$ for 4 min and fractionated on a $6 \%$ denaturing polyacrylamide gel. Amplified fragments were detected by autoradiography using Kodak X-Omat film preflashed so as to obtain a linear relationship between radioactivity and optical densities of the bands. ${ }^{(14)}$ Signals were quantified by densitometric scanning, of suitably exposed autoradiographs on a Hirschmann Elscript 400 apparatus. For each lane, the ratio between mRNA signals (output) from the test and the reference plasmid was calculated and plotted against the ratio of transfecting plasmids (input). The linearity of the relationship was tested by standard linear regression analysis.

\section{RESULTS AND DISCUSSION}

Signal Ratio is a Linear Function of the Ratio of Transfecting Plasmids

The method presented in this paper is based on the prediction that in a given cell line the ratio $y$ between the strength of mRNA signals from the test plasmid $\left(Y_{\mathrm{t}}\right)$ and from the reference plasmid $\left(Y_{\mathrm{r}}\right)$ is a linear function of the input ratio $x$ between the amounts $\left(X_{t}\right.$ and $X_{\mathrm{r}}$ ) of the two co-transfected plasmids, i.e.:

$$
y=C \times x
$$

To test this, we transfected PC60 cells with different ratios of pA62 (Fig. 2A) and the reference plasmid $p G \beta A c \beta$ GID. After $48 \mathrm{hr}$, total cytoplasmic RNA was extracted, reverse-transcribed, and amplified using the specific oligonucleotides P5' and P3' (Fig. 1B). PCR fragments were denatured and fractionated on a sequencing gel. Autoradiographic signals were quantified by densitometry (see Methods).

The amplified fragments derived from the wild type, and deleted $\beta$ globin mRNAs had the predicted lengths of 302 and 262 bases, respectively (Fig. 2B), whereas the same primers amplified segments from the transfecting plasmids with the predicted sizes of 427 (pA62) and 387 bases (pG $\beta A c \beta G I D)$. (Fig. 2B, controls). In certain experiments (see also Fig. 3A), fragments of 427 bases and 387 bases were seen in the RNA samples due to incomplete DNase I digestion. All bands appeared as doublets (better seen in Figs. $3 \mathrm{~A}$ or $6 \mathrm{~A}$ ). Using endlabeled P5' or P3' oligonucleotides separately, we found that the upper band in each doublet corresponds to the plus and the lower band to the minus strand (data not shown). The slower migration of the plus strand is the result of the molecular weight difference between the two strands.

Fractionation of the PCR products on nondenaturing agarose or poly- 
acrylamide gels gave rise to additional bands besides the predicted fragments. These probably correspond predominantly to heteroduplexes between a deleted and a normal cDNA strand. Because they contain a 40-base singlestranded loop, they are expected to migrate differently from homoduplexes. Single-stranded cDNAs forming secondary structures may contribute yet other bands.

We tried to use Vent polymerase (New England Biolabs) instead of Taq polymerase for CDNA amplification. However, we were unable to modify the reverse transcription buffer to make it compatible with Vent polymerase activity. This meant that it was necessary to precipitate the CDNAs before amplification, which tended to result in loss of signal.

Figure 2, C and D, shows that under the conditions described in Methods there is a near-perfect linear correlation $\left(r^{2}=1.0\right)$ between signal ratio and plasmid input ratio. Linear regression analysis gives an intercept close to zero and a slope $(C)$ of 7.9 . For a given test plasmid, $C$ is reproducible in independent experiments. Deviations of the intercept from zero are most likely due to small variations in the background on the autoradiographic film.

$C$ is the product of all factors that affect the output ratio. These include, on the one hand, differences in the synthesis rate $\left(t=T_{\mathrm{t}} / T_{\mathrm{r}}\right)$ and procescing $\left(p=P_{\mathrm{t}} / P_{\mathrm{r}}\right)$ of the transcripts of the two transfecting plasmids or in the half-life ( $h=H_{\mathrm{t}} / H_{\mathrm{r}}$ ) of the resulting mRNAs. In addition, they may also reflect differences in cDNA synthesis $\left(\rho=\rho_{\mathrm{t}} / \rho_{\mathrm{r}}\right)$ and amplification $\left(\alpha=\alpha_{\mathrm{t}} / \alpha_{\mathrm{r}}\right)$. $C$ can be written as:

$$
C=t \times \mathrm{p} \times h \times \rho \times \alpha .
$$

If there are no or undetectable effects of the deletion on any of these parameters and if both plasmids contain the same promoter, $C$ is expected to be 1 . To test this, we co-transfected PC60 cells with two plasmids that contain the chicken $\beta$-actin promoter

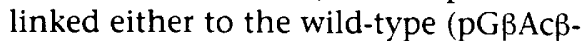
$\mathrm{Gl})$ or to the deleted rabbit $\beta$-globin gene ( $p G \beta A c \beta G I D)$ (Fig. 3A). As seen in the plot in Figure $3 \mathrm{~B}$, the value for the slope $C$ is 2.7 , indicating that the deletion had an influence either on mRNA levels or on the in vitro amplifi-cation steps. To deduce which steps contributed to the deviation of $C$ from 1 , we carried out the experiments described below.

\section{No Difference in the Half-life of the Two mRNAs}

To test whether the two transcripts have a different half-life, we cotransfected PC60 cells with three different ratios of $\mathrm{pG} \beta A \mathrm{Ac} \beta \mathrm{Gl}$ and pGBAcBGID (Fig. 4A). After transfection, cells were split and $42 \mathrm{hr}$ later actinomycin was added to one aliquot of each transfection. Cytoplasmic RNA was prepared from all samples after a further $6 \mathrm{hr}$ and assayed according to the standard protocol. If the deletion in $p G \beta A c \beta G I D$ would have a strong effect on mRNA half-life, we would expect that blocking of mRNA synthesis with actinomycin $D$ would result in a change of $C$. Figure $4 \mathrm{~B}$ shows that $C$ is not significantly affected the actinomycin $\mathrm{D}$ treatment $(C=2.6$ in $\mathrm{ab}$ sence versus $C=2.4$ in presence of actinomycin). Thus, there appears to be no strong influence of the deletion in the reference plasmid on mRNA halflife $(h=1)$.

\section{The Deletion Affects cDNA Synthesis}

To assess the contribution of the amplification step to the deviation of $C$ from 1, we mixed the two plasmids

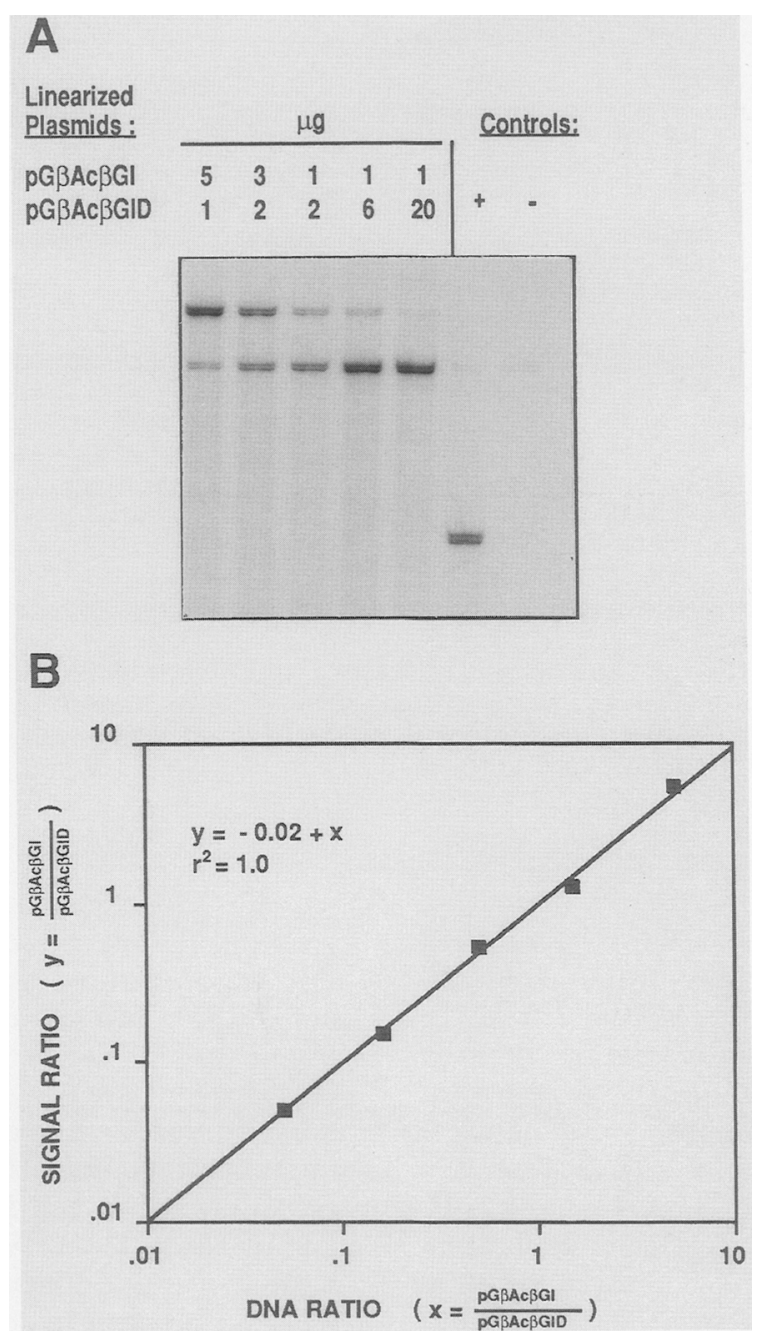

FIGURE 5 No preference in amplification. (A) The two plasmids $p G \beta A c \beta G l$ and $p G \beta A c \beta G I D$ were linearized, mixed in the indicated ratios, and amplified with Taq polymerase. As a positive control, we used pOVEC ${ }^{(15)}$ containing a $\beta$-globin gene in which the first intron has been deleted. The results were plotted on a log-scale $(B)$. 


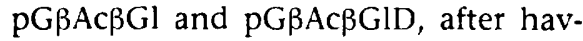
ing linearized them, in different ratios and amplified them with PCR (Fig. 5A). Figure $5 \mathrm{~B}$ shows that after 40 cycles, $\alpha$ $=1.0$. The same is true when the amplified products are quantified after 20 , 25,30 , and 35 cycles (not shown). This means that the deletion in the reference plasmid does not lead to preferential amplification by Taq polymerase.

The deletion of $40 \mathrm{bp}$ in the rabbit $\beta$-globin gene may change the secondary structure of the mRNA, and this, in turn, could lead to a difference in processivity of the reverse transcriptase. To test this, we transfected PC60 cells either with the plasmid pG $\beta A c \beta$ Gl or $p G \beta A c \beta G I D$. Having compared the $\beta$-globin mRNA concentrations in cytoplasmic RNA preparations from these transfections, using RNase protection (not shown), we mixed wildtype and deleted transcripts in defined ratios (Fig. 6A). After cDNA synthesis and amplification with Taq polymerase, we compared signal-to-input mRNA ratio (Fig. 6B). The observed value of $C=2$ is an estimate for the product of $\rho \times \alpha$. Having obtained an estimate of 1.0 for $\alpha$, we conclude that $\rho=2$, i.e., the processivity of the reverse transcriptase is two times higher using the wild-type mR.i.t as template.

This difference is the main contribution to the deviation of $C$ from 1 . Since $C=2.7=2^{\star} t \times p, t \times p$ is estimated to be 1.4. Assuming that the deletion has little or no effect on the rate of RNA synthesis (transcript initiation and elongation; i.e., $t=1$ ), we conclude that processing is only slightly affected $(p=1.4)$.

\section{CONCLUSIONS}

The assay described here uses PCR to measure reporter gene expression, and hence provides an alternative to RNase protection. The PCR assay is faster and technically simpler. Comparison of the amount of RNA from transfected cells required to produce detectable signals in RNase protection and using the method described here showed that the latter is at least 1000 times more sensitive (not shown). One disadvantage of the PCR assay is that it does not permit direct mapping of transcription start sites. However, it is at least possible to check for read- through transcripts from abnormal start sites in promoter constructs by using oligonucleotides corresponding to plasmid sequences upstream of the normal transcription start site(s).

As shown here it is simple to verify the validity of the PCR assay in any given experimental system by checking that signal ratio is a linear function of plasmid input ratio. In analyses of cisacting elements responding to extracellular stimuli, one can test whether these stimuli have a different effect, e.g., on the half-life of the wild- type and of the deleted mRNA, by checking whether $C$ is affected by stimulation when both plasmids have the same promoter. Once these preliminary controls have been carried out, the activity of different promoter constructs can be compared using a single appropriately chosen input ratio between test and reference plasmids. From the experiments shown here (see, e.g, Fig. 2), we expect that with a single ratio 100 -fold differences in the activity of promoter constructs can be measured reliably. Experiments using

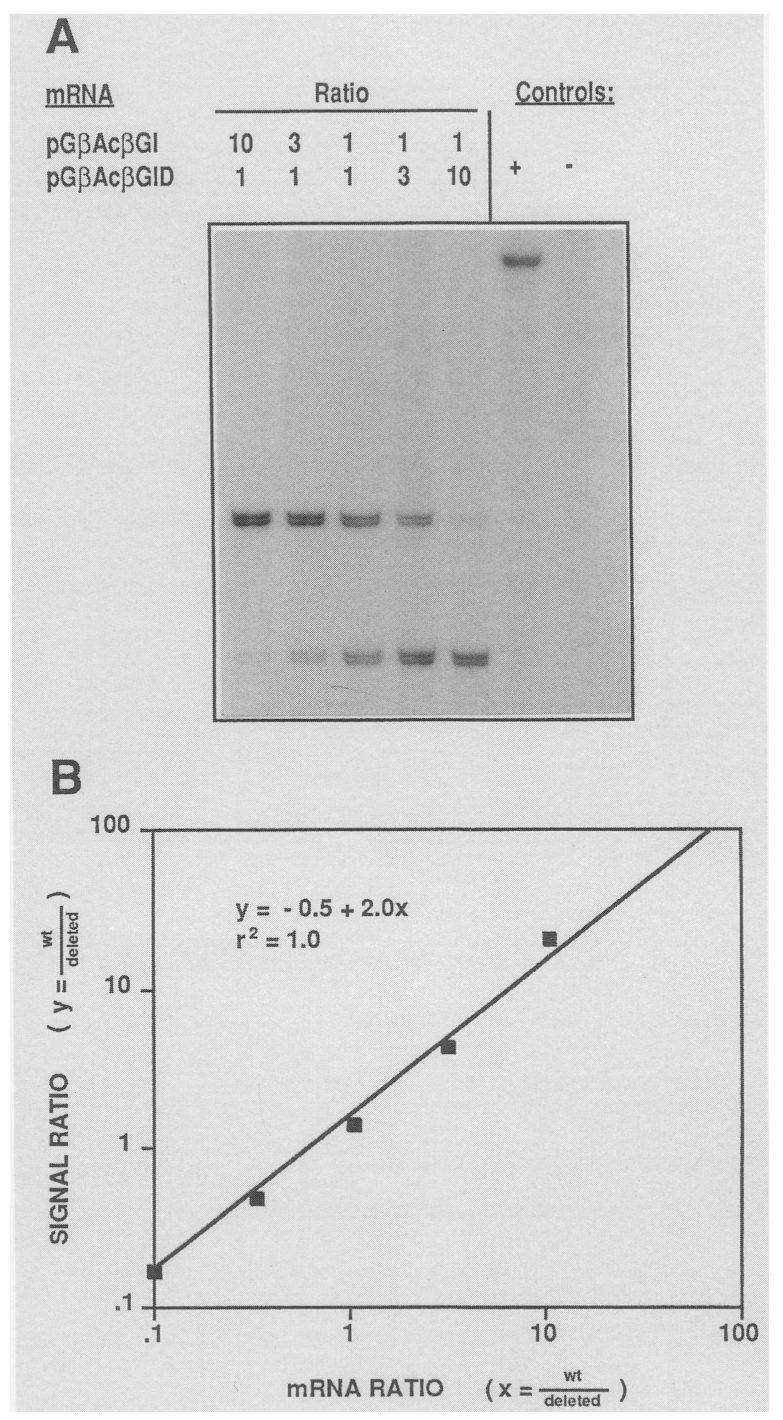

FICURE 6 Higher processivity of AMV reverse transcriptase on wild-type mRNA. (A) PC60

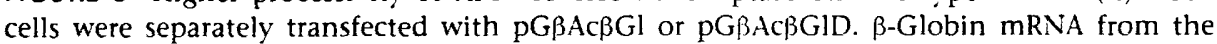
two transfections was quantified by RNase protection and mixed in different ratios, as indicated above the lanes. The mixtures were reverse-transcribed and amplified. Controls are the same as described in Fig. 3A. (B) Plot of the signal versus input mRNA ratios. 
different SV40 enhancer recombinants have shown that this is indeed the case (data not shown). The assay will greatly facilitate the analyses of weak promoters and will allow reliable transient transfection studies in experimental systems where limited numbers of recipient cells are available. We have, indeed, already used the method to quantify transcript levels from several promoters that did not give detectable signals by RNase protection (A.-L. Lattion et al., in prep), and have successfully measured reporter gene expression in antigen-dependent T-lymphocyte clones that were difficult to analyze by other methods. The assay has also been used to analyze reporter gene expression in fibroblasts transfected by the calcium phosphate method.

The method should also be adaptable to the study of cis-acting elements affecting other components of gene expression.

\section{ACKNOWLEDGMENTS}

We thank C. Weissmann, M. Collins, and P. Chambon for gifts of plasmids; M. Allegrini and P. Dubied for preparing the figures; A. Emery-Goodman for synthesizing the oligonucleotides; and C. Ravussin for helping with the preparation of the manuscript. This work was supported by a grant from the Swiss Cancer League.

\section{REFERENCES}

1. Chelly, J., J.-C. Kaplan, P. Maire, S. Gautron, and A. Kahn. 1988. Transcription of dystrophin gene in human muscle and non-muscle tissues. Nature 333: 858-860.

2. Chelly, J., J.-P. Concordet, J.-C. Kaplan, and A. Kahn. 1989. Illegitimate transcription: Transcription of any gene in any cell. Proc. Natl. Acad. Sci. 86: 2617-2621.

3. Sarkar, G. and S.S. Sommer. 1989. Access to a messenger RNA sequence or its protein product is not limited by tissue or species specificity. Science 244: 331-334.

4. Gilliland, G., S. Perrin, K. Blanchard, and H.F. Bunn. 1990. Analysis of cytokine mRNA and DNA: Detection and quantitation by competitive polymerase chain reaction. Proc. Natl. Acad. Sci. 87: 2725-2729.
5. Espel, E., C. Fromental, P. Reichenbach, and M. Nabholz. 1990. Activity and interleukin 1 responsireness of SV+0 enhancer motifs in a rodent immature $T$ cell line. E.MBO $/$. 9: 929-937.

6. Zenke, M., T. Grundström, H. Matthes, M. Wintzerith, C. Schatz, A. Wildeman, and P. Chambon. 1986. Multiple sequence motifs are involved in SV40 enhancer function. EMBO J. 5: 387-397.

7. Collins, M.K.L., P. Malde, A. Mivajima, K.-I. Arai, K.A. Smith, and R.C. Mulligan. 1990. Evidence that the level of the p55 component of the interleukin 2 receptor can control II. 2 responsiveness in a murine IL 3 dependent cell. Eur. J. Immumol. 20: 573-578.

8. Kost, T.A., N. Theodorakis, and S.H. Hughes. 1983. The nucleotide sequence of the chicken cytoplasmic beta-actin gene. Nucleic Acids Res. 11: 8287-8301.

9. van den Berg, J., A. van Ooyen, N. Mantei, A. Schamböck, G. Grosveld, R.A. Flavell, and C. Weissmann. 1978. Comparison of cloned rabbit and mouse beta-globin gene showing strong evolutionary divergence of two homologous pairs of introns. Nature 276: 37-44.

10. Conzelmann, A., P. Corthésy, $M$. Cianfriglia, A. Silva, and M. Nabholz. 1982. Hybrids between rat lymphoma and mouse $\mathrm{T}$ cells with inducible cytolytic activity. Nature 298: 170172.

11. Silva, A., H.R. MacDonald, A. Conzelmann, P. Corthésy, and $M$. Nabholz. 1983. Rat $x$ mouse T-cell hybrids with inducible specific cytolytic activity. Immunol. Rev. 76: 105-129.

12. Queen, C. and D. Baltimore. 1983. Immunoglobulin gene transcription is activated by downstream sequence elements. Cell 33: 741-748.

13. Gough, N.M. 1988. Rapid and quantitative preparation of cytoplasmic RNA from small numbers of cells. Anal. Biochem. 173: 93-95.

14. Laskey, R.A. and A.D. Mills. 1975. Quantitative film detection of ${ }^{3} \mathrm{H}$ and ${ }^{14} \mathrm{C}$ in polyacrylamide gels by fluorography. Eur. J. Biochem. 56: 335-341.

15. Westin, G., T. Gerster, M.M. Müller, G. Schaffner, and W. Schaffner. 1987. OVEC, a versatile system to study transcription in mammalian cells and cell-free extracts. Nucleic Acids Res. 15: $6787-6798$.

Received November 11, 1991; accepted in revised form December 24, 1991. 


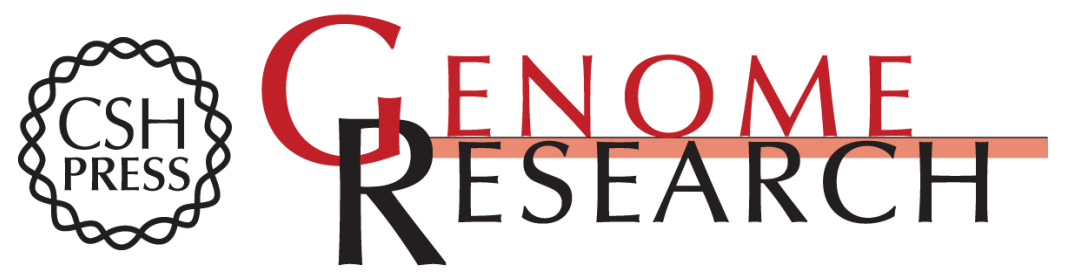

\section{A PCR-based assay for reporter gene expression.}

P Sperisen, S M Wang, P Reichenbach, et al.

Genome Res. 1992 1: 164-170

Access the most recent version at doi:10.1101/gr.1.3.164

References This article cites 15 articles, 3 of which can be accessed free at:

http://genome.cshlp.org/content/1/3/164.full.html\#ref-list-1

\section{License}

Email Alerting Receive free email alerts when new articles cite this article - sign up in the box at the Service top right corner of the article or click here.

\section{Affordable, Accurate Sequencing.}

To subscribe to Genome Research go to: https://genome.cshlp.org/subscriptions 